Radiochemical tracers as a mix diagnostic for the ignition double-shell capsule

J. Colvin, C. Cerjan, R. Hoffman, M. A. Stoyer, P. Amendt

May 14,2010

NEDPC

Livermore, CA, United States

October 26, 2009 through October 30, 2009 
This document was prepared as an account of work sponsored by an agency of the United States government. Neither the United States government nor Lawrence Livermore National Security, LLC, nor any of their employees makes any warranty, expressed or implied, or assumes any legal liability or responsibility for the accuracy, completeness, or usefulness of any information, apparatus, product, or process disclosed, or represents that its use would not infringe privately owned rights. Reference herein to any specific commercial product, process, or service by trade name, trademark, manufacturer, or otherwise does not necessarily constitute or imply its endorsement, recommendation, or favoring by the United States government or Lawrence Livermore National Security, LLC. The views and opinions of authors expressed herein do not necessarily state or reflect those of the United States government or Lawrence Livermore National Security, LLC, and shall not be used for advertising or product endorsement purposes. 


\title{
UNCLASSIFIED
}

\section{Radiochemical Tracers as a Mix Diagnostic for the Ignition Double-Shell Capsule (U)}

\author{
Jeffrey Colvin, Charles Cerjan, Robert Hoffman, Mark Stoyer, and Peter Amendt \\ Lawrence Livermore National Laboratory, P.O. Box 808, Livermore, CA 94551
}

One of the most important challenges confronting laser-driven capsule implosion experiments will be a quantitative evaluation of the implosion dynamics. Since these experiments will encounter extreme conditions of pressure and temperature, establishing robust, sensitive diagnostics will be difficult. Radiochemical signatures provide insight into material mixing and laser drive asymmetry and complement $x$-ray and other nuclear diagnostics, since the relevant nuclear reactions sample core implosion conditions directly. Simulations of an ignition double shell target indicate that several experimentally accessible isomeric ratios will be suitable monitors of mix. (Unclassified)

\section{NEDPC Poster}

This NEDPC poster was already published ${ }^{1}$ and discussed in much more detail therein.

\section{Conclusions}

The generally acknowledged importance of material mix as a degradation mechanism for ignition capsules motivates the search for reliable diagnostic techniques that will quantify this effect. Since the effects of the mixed material on the implosion dynamics are indirect, straightforward x-ray or neutron imaging will have difficulty discriminating the mix contributions from other degradation modes such as x-ray flux asymmetry. Hence, the development of nuclear diagnostics that directly sample the core conditions near the time of peak burn might prove to be the most effective approach. Indeed, the recent development of $\mathrm{D}^{3} \mathrm{He}$-proton spectroscopy as a mix diagnostic supports this view. The use of radiochemical tracers introduced near the fuel core represents another such nuclear diagnostic, since an appropriate choice of reaction products will provide information about the imploding core at precisely the times when the effects of mix are most important. Furthermore, different types of nuclear reactions may be chosen to sample different spatial regions.

This approach has been demonstrated above in the case of alpha- and deuteron-induced reactions. These choices are differentially sensitive to the immediate core region and the surrounding shell material, thus providing important, quantitative information about the implosion conditions. Of course other reaction types might be useful, such as neutron mediated reactions like $(n, 2 n)$ or $(n, \gamma)$ interactions. These neutrons would sample all of the dense remaining material due to their very long interaction ranges. Future work will be devoted to the development of suitable reaction sets for this class of reactions.

\section{Acknowledgments}

This work was performed under the auspices of the U.S. Department of Energy by Lawrence Livermore National Laboratory in part under Contract W-7405Eng-48 and in part under Contract DE-AC5207NA27344 with support received from LDRD Project \#05-SI-005.

\section{References}

1. J. Colvin, C. Cerjan, R. Hoffman, M.A. Stoyer, and P. Amendt, Phys. of Plasmas 15 (2008) 102704. 